\title{
CHARACTERISTICS OF THE IONOSPHERE AND THEIR APPLICATION TO RADIO TRANSMISSION
}

\author{
By Theodore R. Gilliland, Samuel S. Kirby, Newbern Smith, and \\ Stephen E. Reymer
}

\section{ABSTRAC'T}

Results of ionosphere measurements near Washington, D. C., made at normal incidence over the period May 1934 to December 1936, inclusive, are presented in graphical form as monthly averages for each hour of the day. The general forms of the diurnal and seasonal variations of the critical frequencies and virtual heights have recurred from year to year. In addition to the seasonal variation there has been a continuous long-time increase of critical frequencies which is associated with the 11-year sunspot cycle. Data are given only for those layers which are fairly regular in behavior - the normal $E, F, F_{1}$, and $F_{2}$ layers.

The interpretation of properties of the ionosphere in terms of radio transmission over medium and long distances is discussed. The properties considered are absorption, virtual height, and critical frequency. It is pointed out that the long-time increase of critical frequencies indicates a corresponding rise in useful transmission frequencies. The paper also describes briefly two types of irregular disturbances of the ionosphere which affect radio transmission.

\section{CONTENTS}

Page

I. Introduction $\ldots \ldots \ldots 45$

II. Virtual heights

III. Critical frequencies_ _. _ _ _ _ _ _

IV. Long-time effects

V. Interpretation and applications

VI. Transmission irregularities

VII. Conclusions _... 667

\section{INTRODUCTION}

A program of measurement of critical frequencies and virtual heights of the ionosphere has been carried on at Washington, D. C., by the National Bureau of Standards since January 1930. Results have been given from time to time in a number of published papers. One of these papers ${ }^{1}$ gives systematic data on critical frequencies of the various regions of the ionosphere for the year May 1933 to April 1934, inclusive. These data were obtained with the multifrequency automatic recorder originated and developed ${ }^{2}$ at the National Bureau of Standards in 1932. Experimental evidence of the beginning of a long-time increase of average critical frequencies was also given in that paper.

The use of the multifrequency automatic recorder has made it possible to secure hourly ionosphere records at the National Bureau

\footnotetext{
1 T. R. Gilliland, Multifrequency ionosphere recording and its significance. J. Research NBS 14, 283 (1935); Proc. Inst. Radio Engrs. 23, 1076 (1935).

2 T. R. Gilliland, Note on a multifrequency automatic recorder of ionosphere heights. BS J. Research 11, 561 (1933); Proc. Inst. Radio Engrs. 22, 236 (1934).
} 
of Standards since May 1933. The recent adoption of the idea of multifrequency automatic recording and the principle of this recorder by the Carnegie Institution of Washington, British Radio Research Board, Australian Radio Research Board, and Harvard University will increase enormously the continuity and value of ionosphere data, which will, in turn, greatly increase our understanding of world-wide ionosphere and radio transmission conditions.

The graphs of the present paper present the results of observations continued since April 1934 through December 1936 and an extension of the $F$ data to each hour of the day. The average, for each hour, of the critical frequencies and virtual heights of the three principal strata, the normal $E, F_{1}$, and $F_{2}$ regions, is given for each month. Curves are not plotted for the sporadic $E$, since its appearance was so erratic that average results would not be reasonably dependable, although it is known that sporadic $E$ frequently determined the upper frequency limit of sky-wave transmission, especially during the summer. These graphs are intended to show the average diurnal variation of ionosphere characteristics for each month of the year, as well as longperiod changes. It is believed that the information will be useful in predicting propagation conditions.

Following the precedent established in earlier papers, the critical frequency for the ordinary ray is given for the $F_{1}$ layer, while that for the extraordinary ray is given for the $F_{2}$ and $F$ layers. In the case of the $F_{1}$ layer the ordinary ray is the more suitable for the purpose of averaging since it is much stronger and is therefore more frequently observed than the extraordinary ray. With regard to the $F_{2}$ and $F$ layers the critical frequency for the extraordinary ray is, with the exception of irregular scattered reflection, the highest frequency returned at normal incidence. Its value gives a measure of the highest usable frequency for short-distance transmission. For longdistance transmission the extraordinary ray may however be expected to extend the usable frequency limit very little, if any, above that for the ordinary ray. If the critical frequency for either ray is known, that for the other may be determined by a simple calculation. At Washington the critical frequency for the extraordinary ray is roughly $800 \mathrm{kc} / \mathrm{s}$ higher than that for the ordinary ray, for ordinary-ray critical frequencies above $2,500 \mathrm{kc} / \mathrm{s}$.

The graphs represent measurements obtained both with the multifrequency automatic recorder and by manual observations. The automatic recorder was arranged to cover the frequency band 2,500 to $4,400 \mathrm{kc} / \mathrm{s}$ once each hour. The manual measurements were usually made during one day each week and principally at frequencies above $4,400 \mathrm{kc} / \mathrm{s}$.

The results of the manual observations are averages for a 60minute interval centered on the hour. The automatic records began on the hour and lasted $43 / 4$ minutes. Although the upper limit of the automatic recorder was $4,400 \mathrm{kc} / \mathrm{s}$, the critical frequency for the extraordinary ray could be determined to as high as $5,200 \mathrm{kc} / \mathrm{s}$, by the $800 \mathrm{kc} / \mathrm{s}$ separation relation mentioned above. Since December 1935 , the multifrequency records have been supplemented by measurements with a fixed-frequency recorder operating either on 7,250 or $6,200 \mathrm{kc} / \mathrm{s}$, giving a record of a few seconds duration every $4 \frac{1}{2}$ minutes. 
The symbols used are:

$h_{B}=E$-region virtual height (lowest measured height).

$h_{P_{1}}=F_{1}$-region virtual height (lowest measured height).

$h_{F_{2}}=F_{2}$-region virtual height (lowest measured height).

$h_{F}=$ night $F$-region virtual height (lowest measured height).

$f_{B}=E$-region critical frequency, in kilocycles per second, ordinary ray.
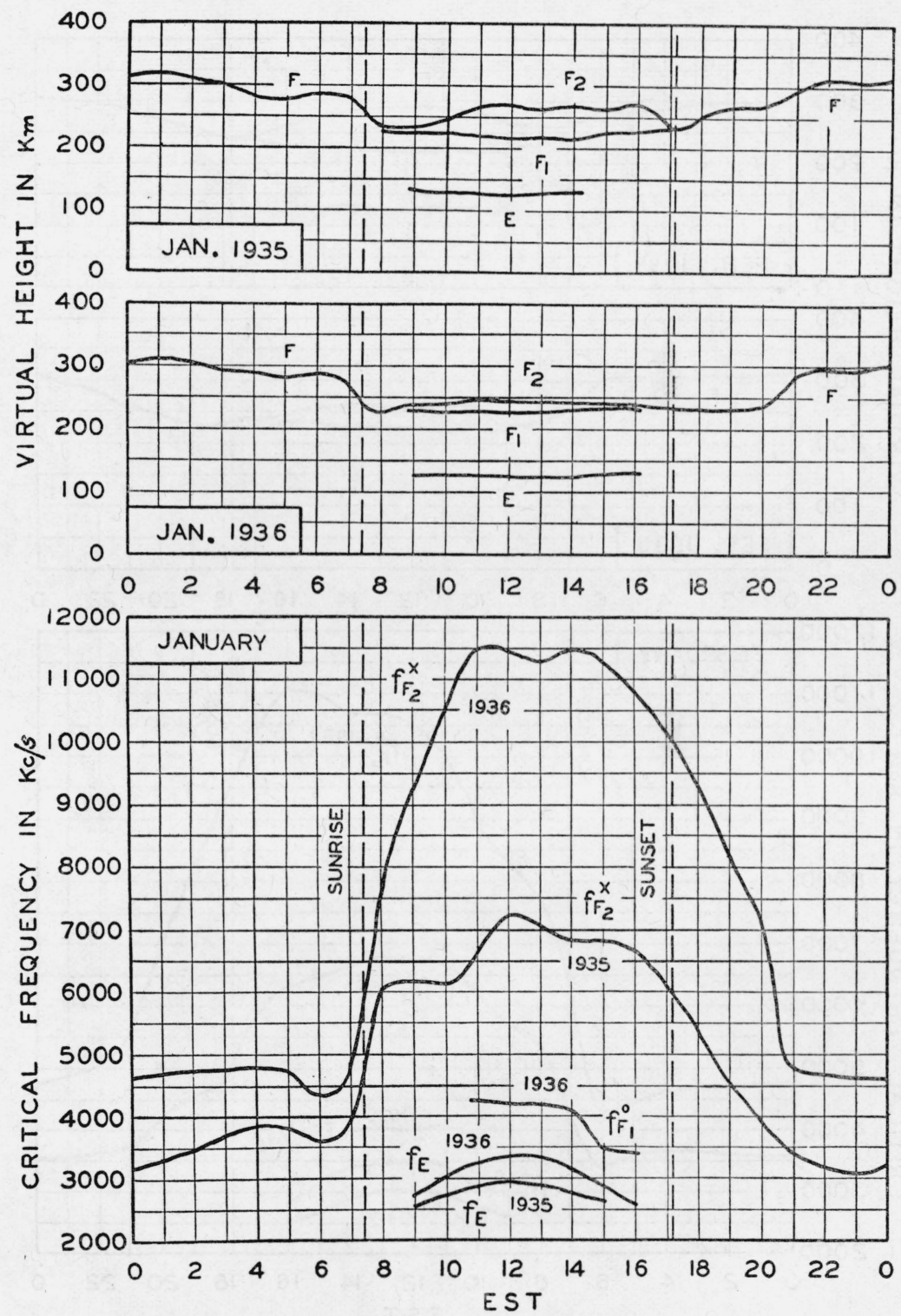

FIGURE 1.-Critical frequencies and virtual heights for January. Curves represent hourly averages. 
$f_{F_{1}}^{0}=F_{1}$-region critical frequency, in kilocycles per second, ordinary ray.

$f_{F_{2}}^{x}=F_{2}$-region critical frequency, in kilocycles per second, extraordinary ray.

$f^{x}=$ night- $F$-region critical frequency in kilocycles per second, extraordinary ray.

$\mathrm{EST}=$ eastern standard time $\left(=75^{\circ}\right.$ west meridian time $)$.

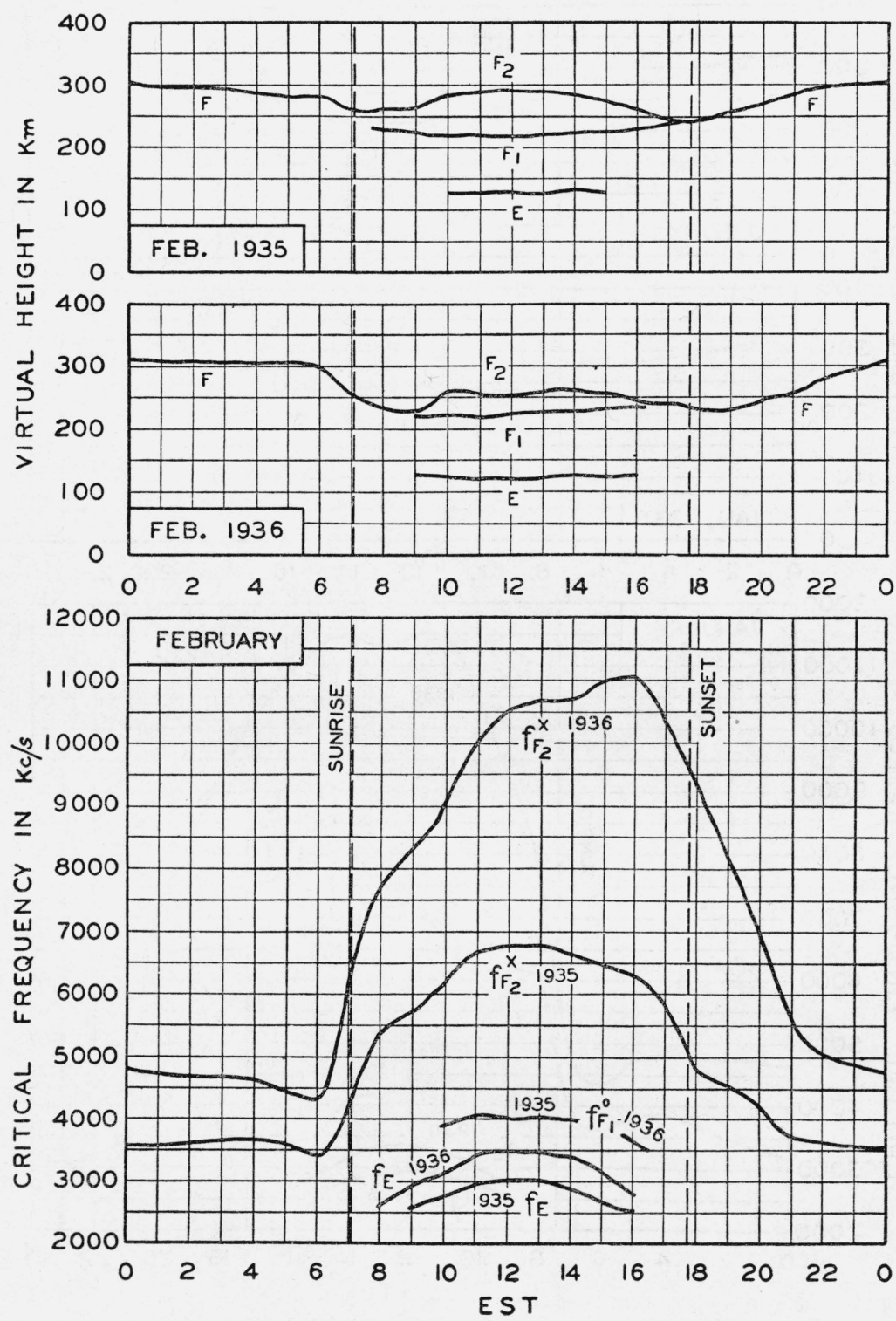

FIgURE 2.-Critical frequencies and virtual heights for February. Curves represent hourly averages. 
Figures 1 to 15 , inclusive, give the hourly averages of critical frequencies and minimum virtual heights for the $E, F_{1}$, and $F_{2}$ regions of the ionosphere for each month of the year from May 1934 to December 1936. For a given month the several years are plotted on the same figure through September 1936. This arrangement makes it easy to see changes which have occurred from year to year. October to December 1936 were plotted separately because the scale already in use was inadequate for the higher critical frequencies.

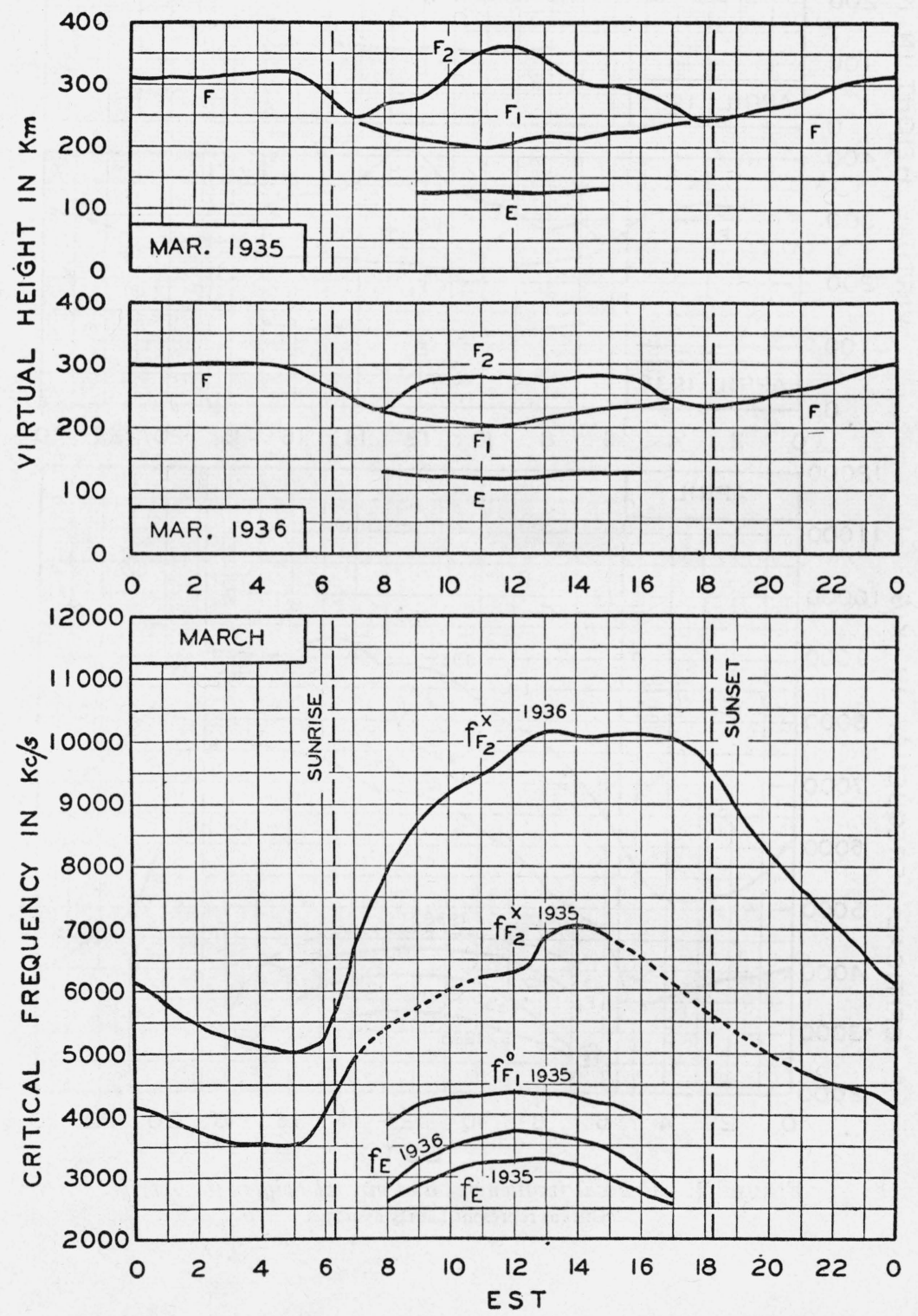

FIGURE 3.-Critical frequencies and virtual heights for March. Curves represent hourly averages. 

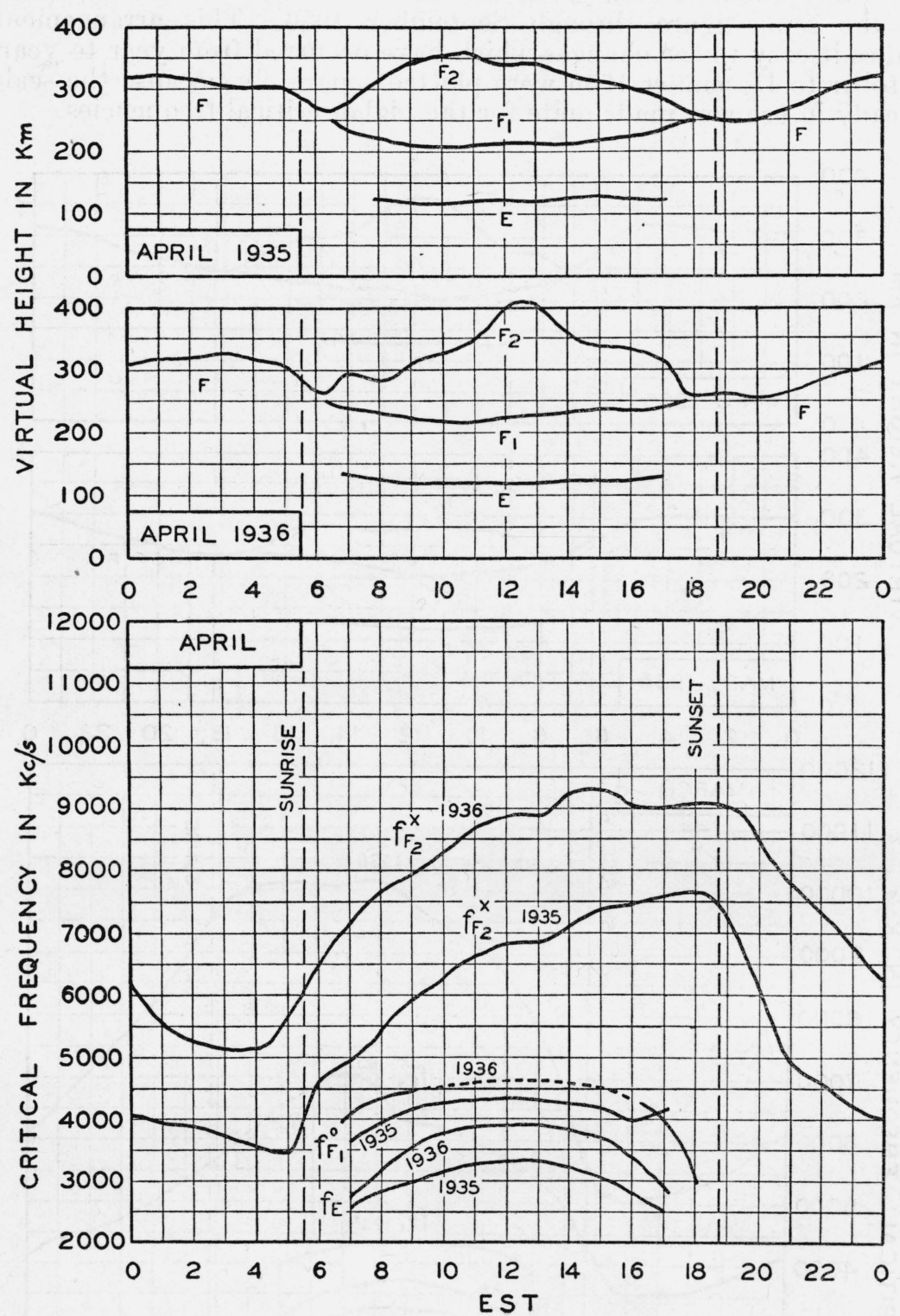

Figure 4.-Critical frequencies and virtual heights for April. Curves represent hourly averages. 


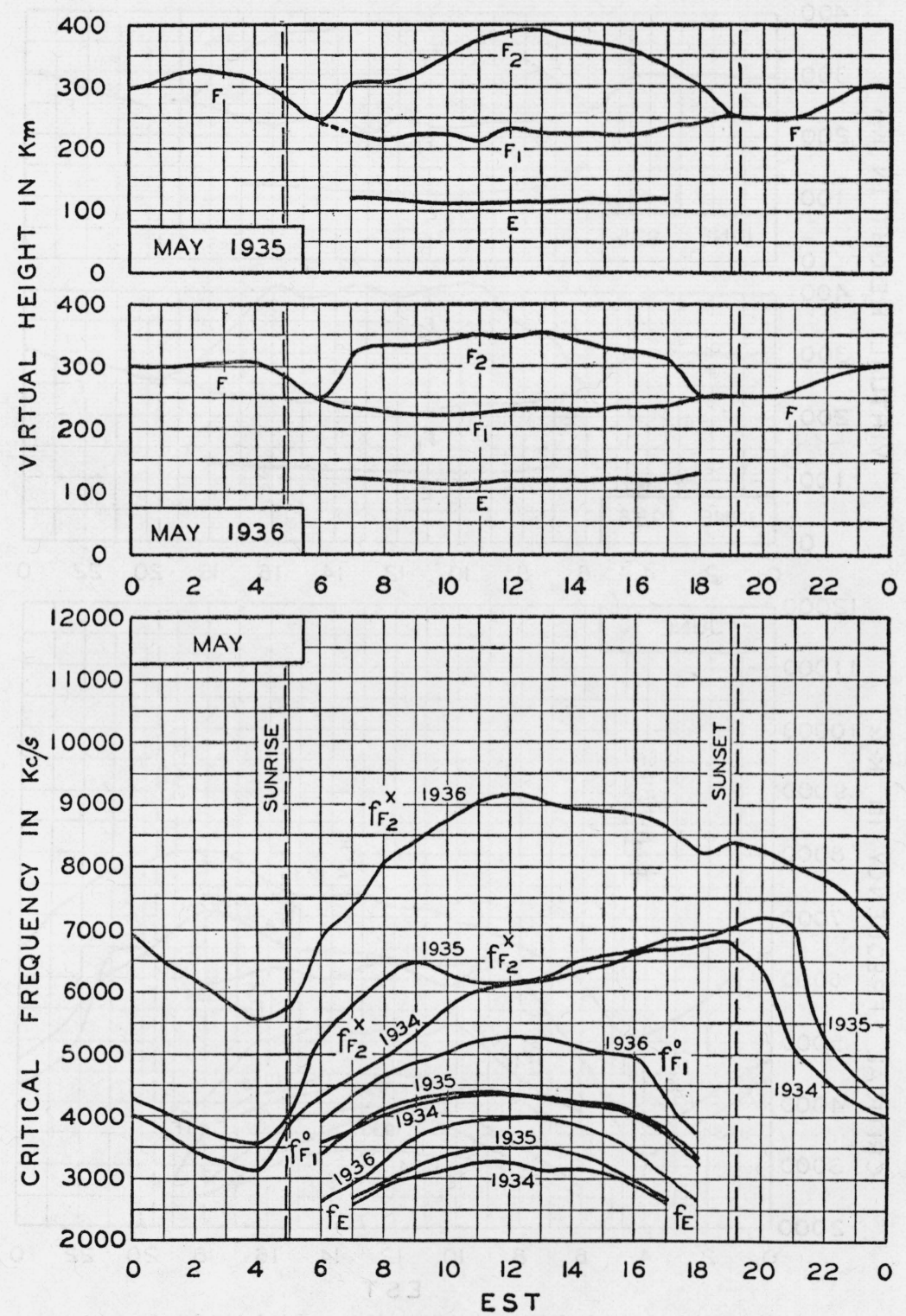

Figdre 5.-Critical frequencies and virtual heights for May. Curves represent hourly averages. 

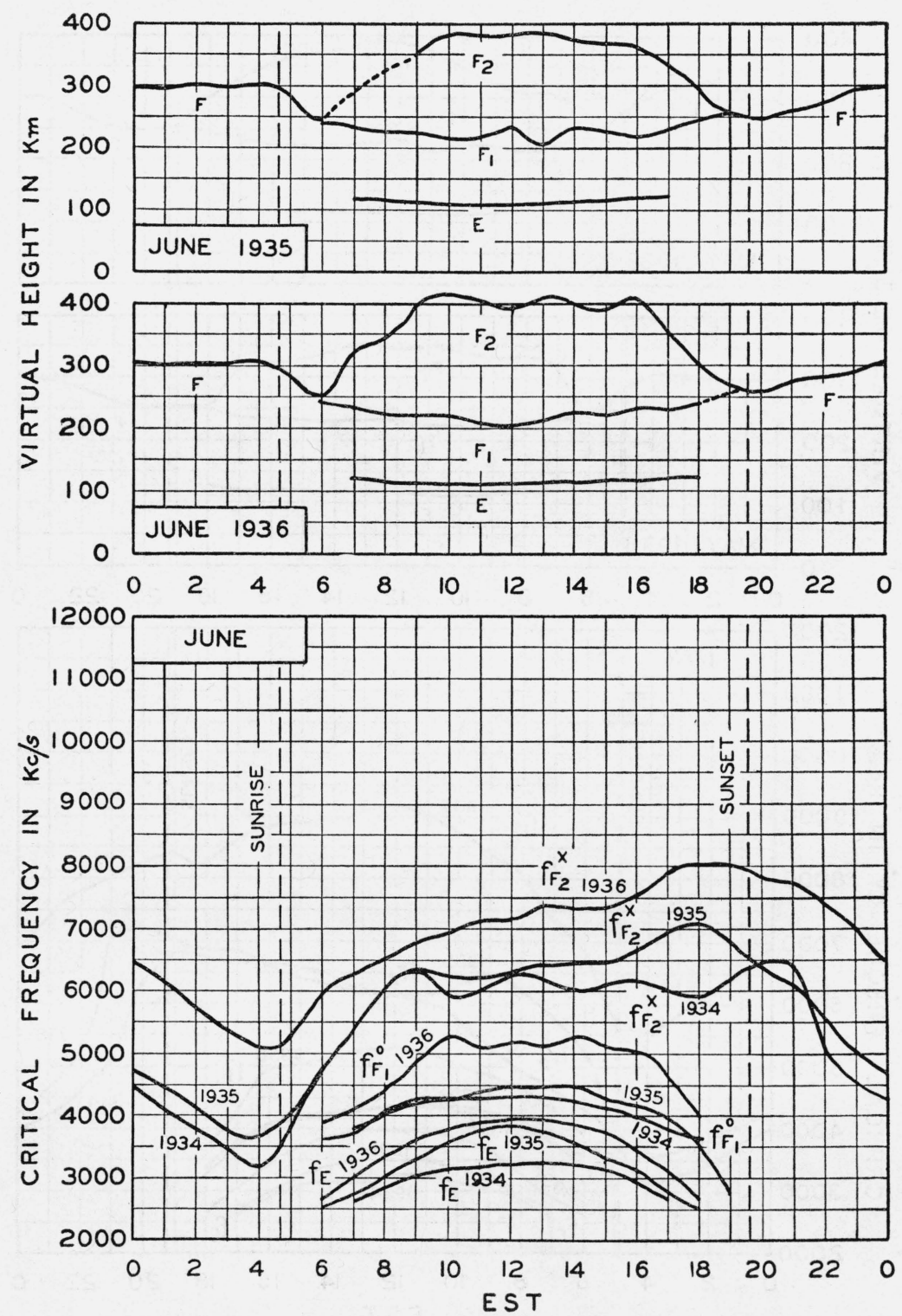

FiguRe 6.-Critical frequencies and virtual heights for June. Curves represent hourly averages. 

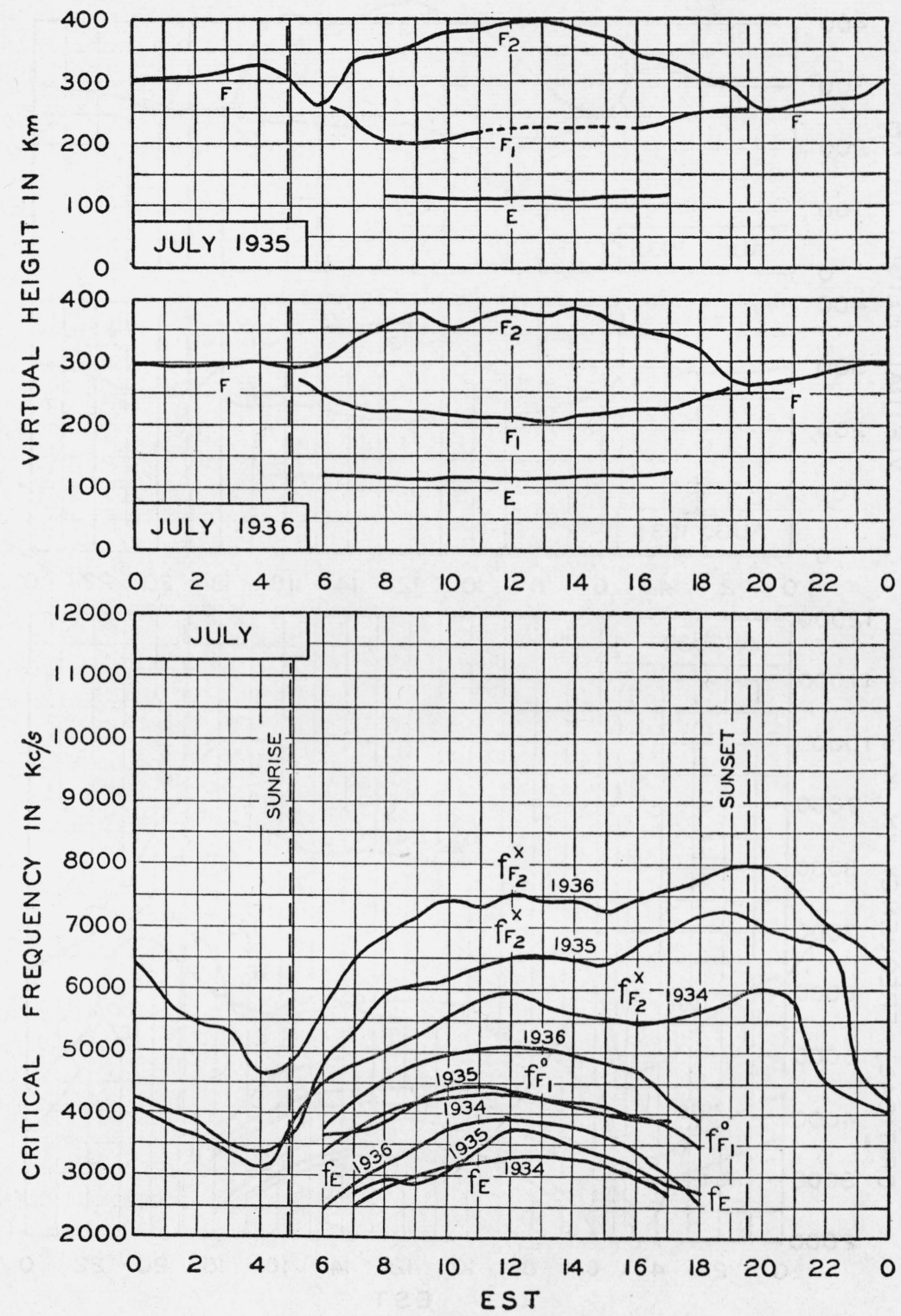

FIgURe 7.-Critical frequencies and virtual heights for July. Curves represent hourly averages. 

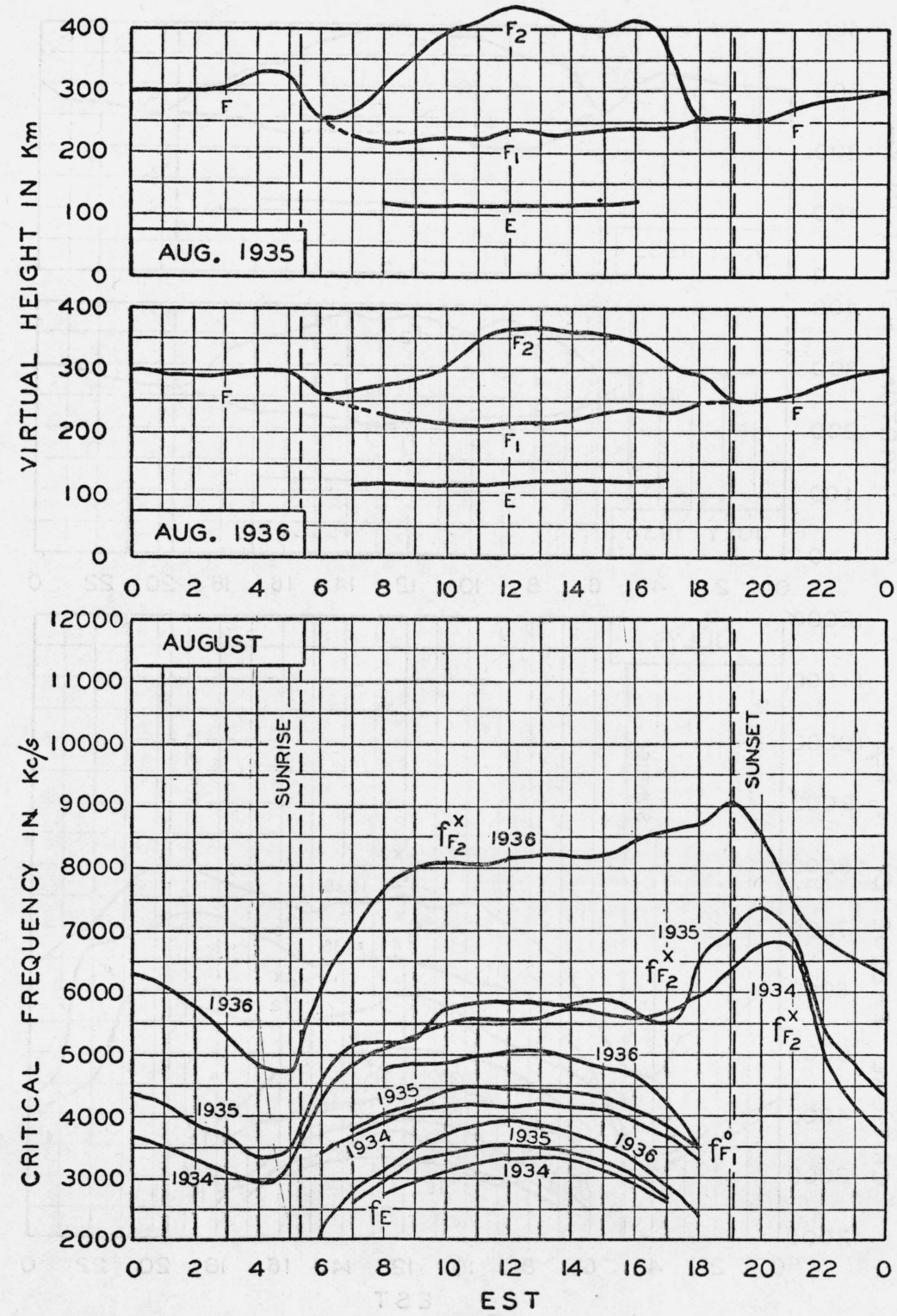

FigdRe 8.-Critical frequencies and virtual heights for August. Curves represent hourly averages. 

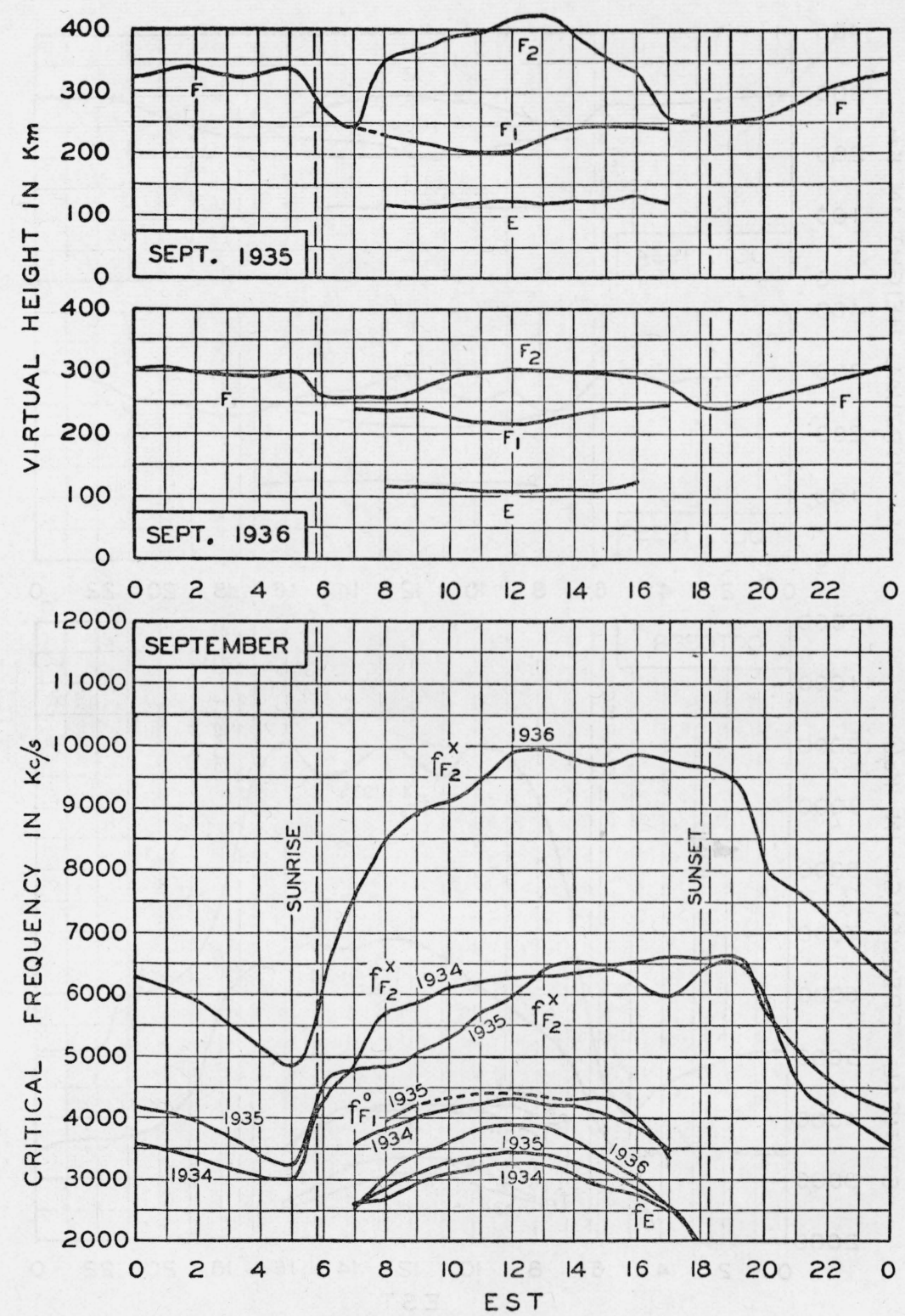

Figure 9.-Critical frequencies and virtual heights for September. Curves represent hourly averages. 

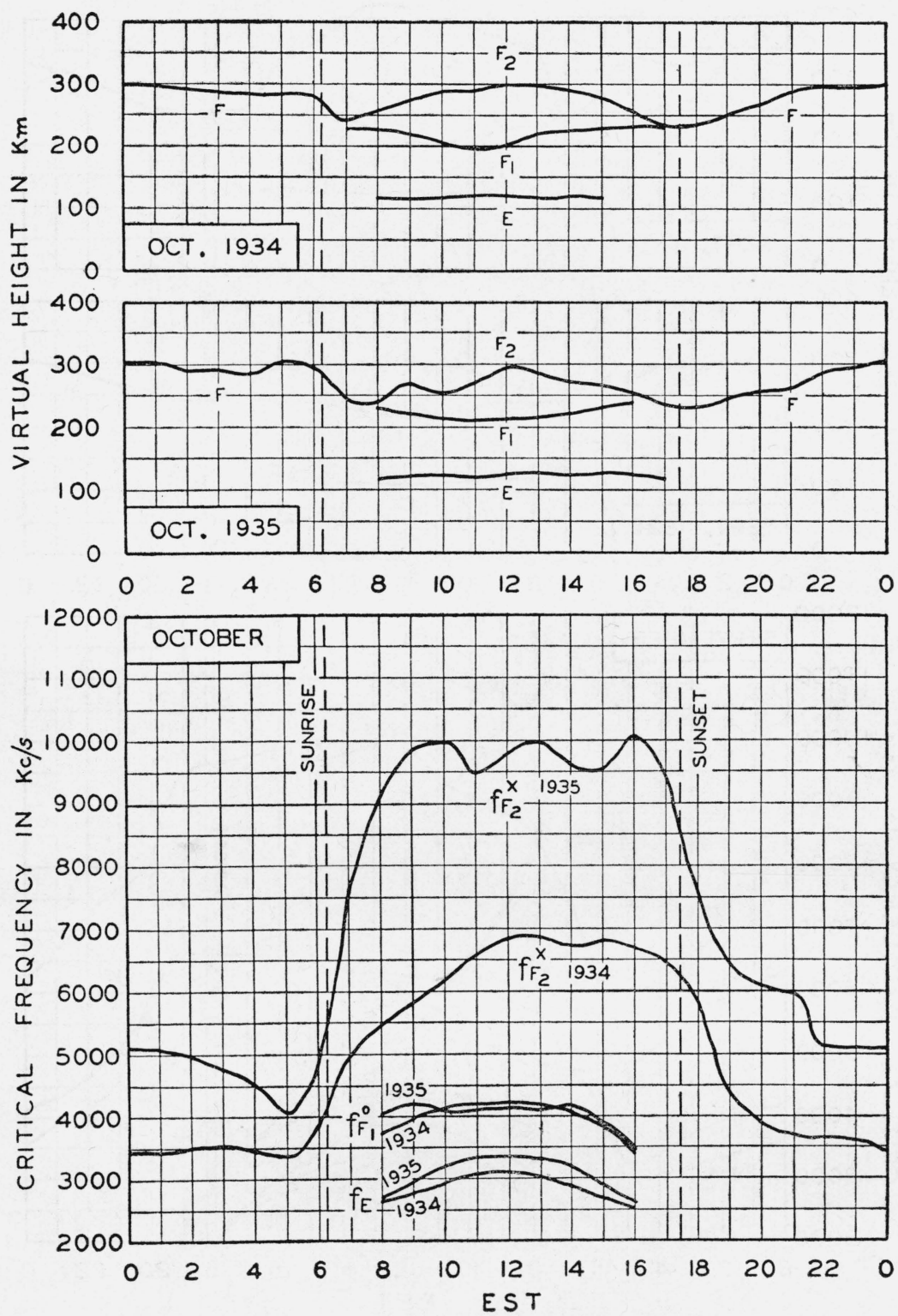

FIGURE 10.-Critical frequencies and virtual heights for October. Curves represent hourly averages. 

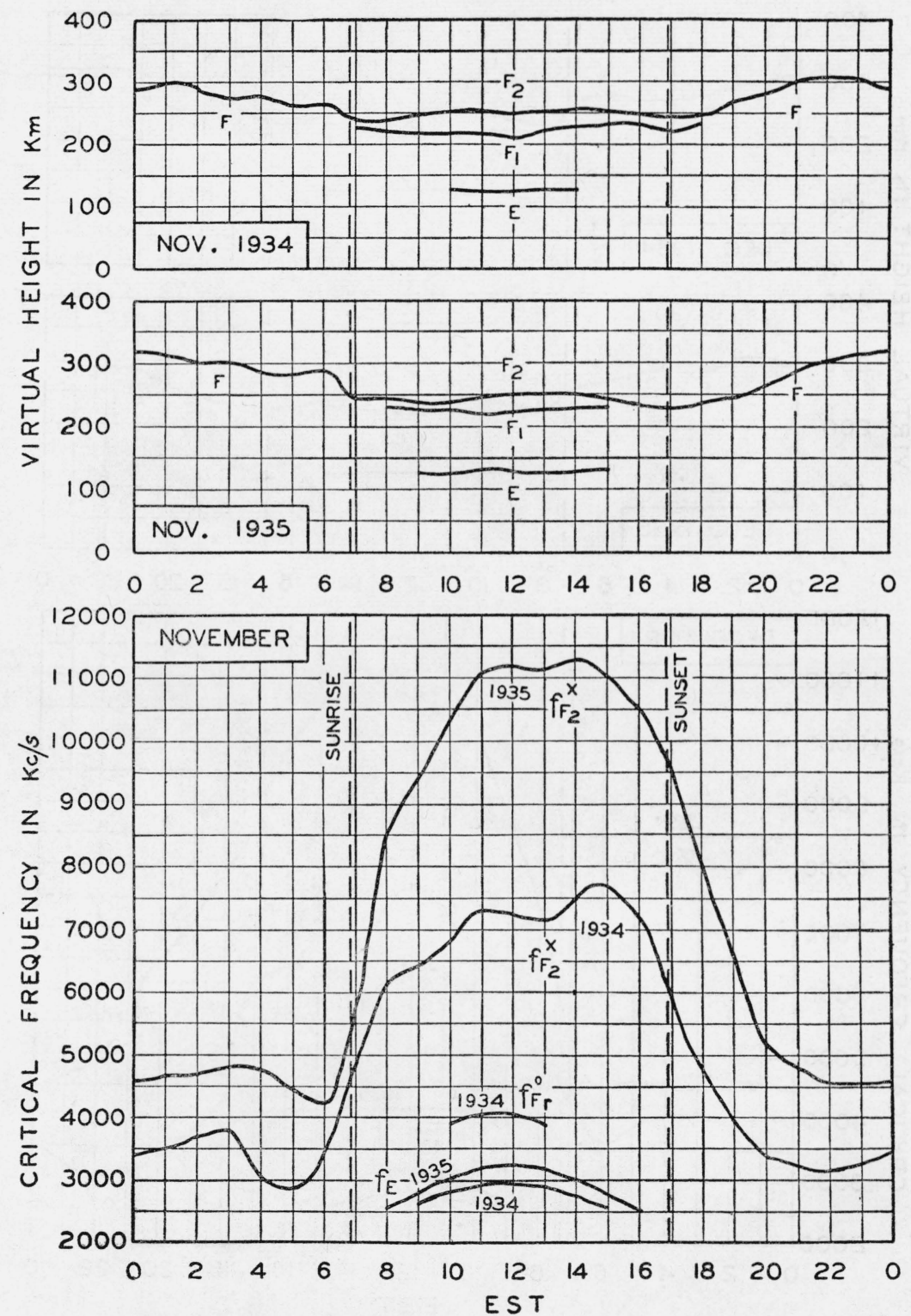

Figure 11.-Critical frequencies and virtual heights for November. Curves represent hourly averages. 


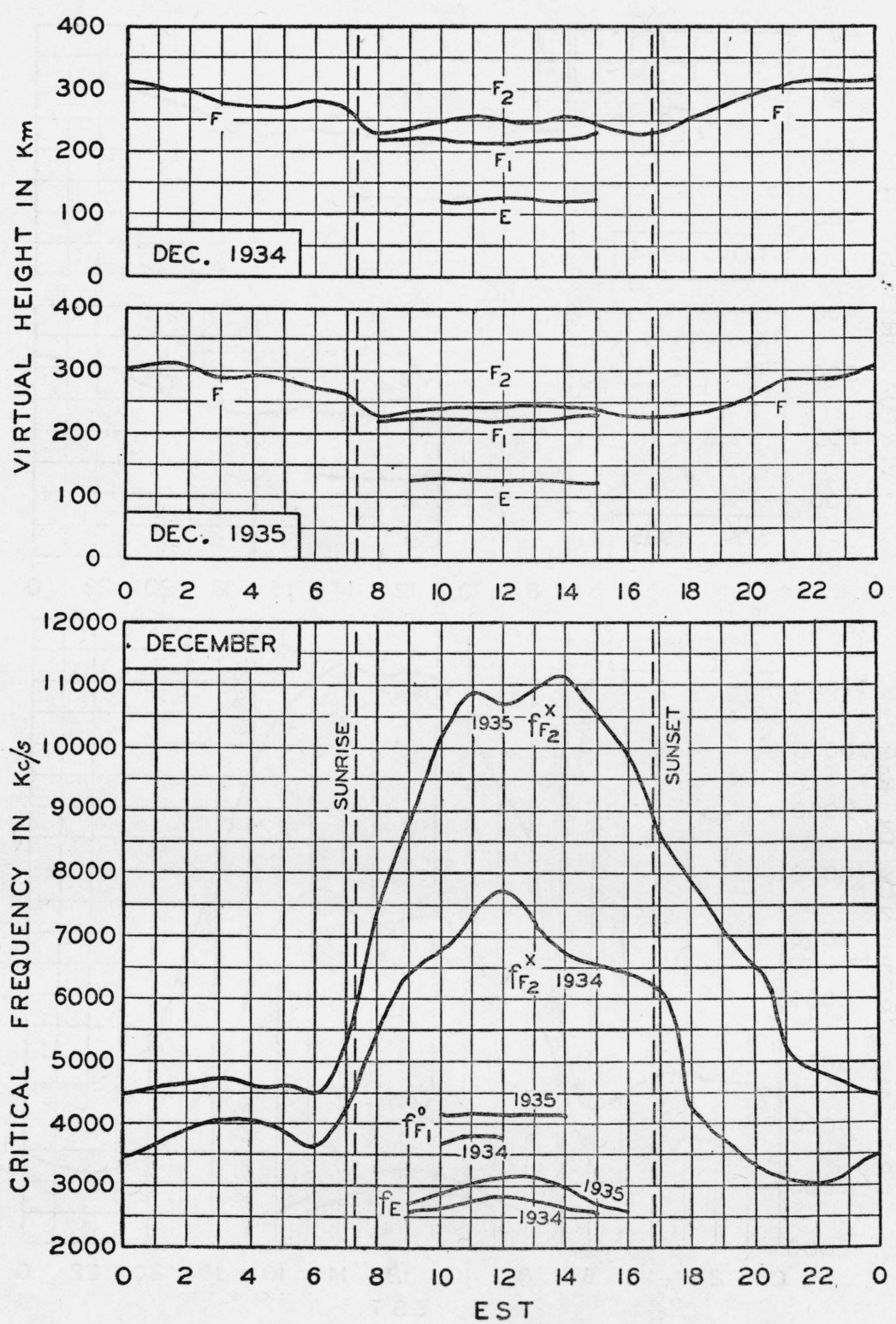

Figure 12. Critical frequencies and virtual heights for December. Curves represent hourly averages. 

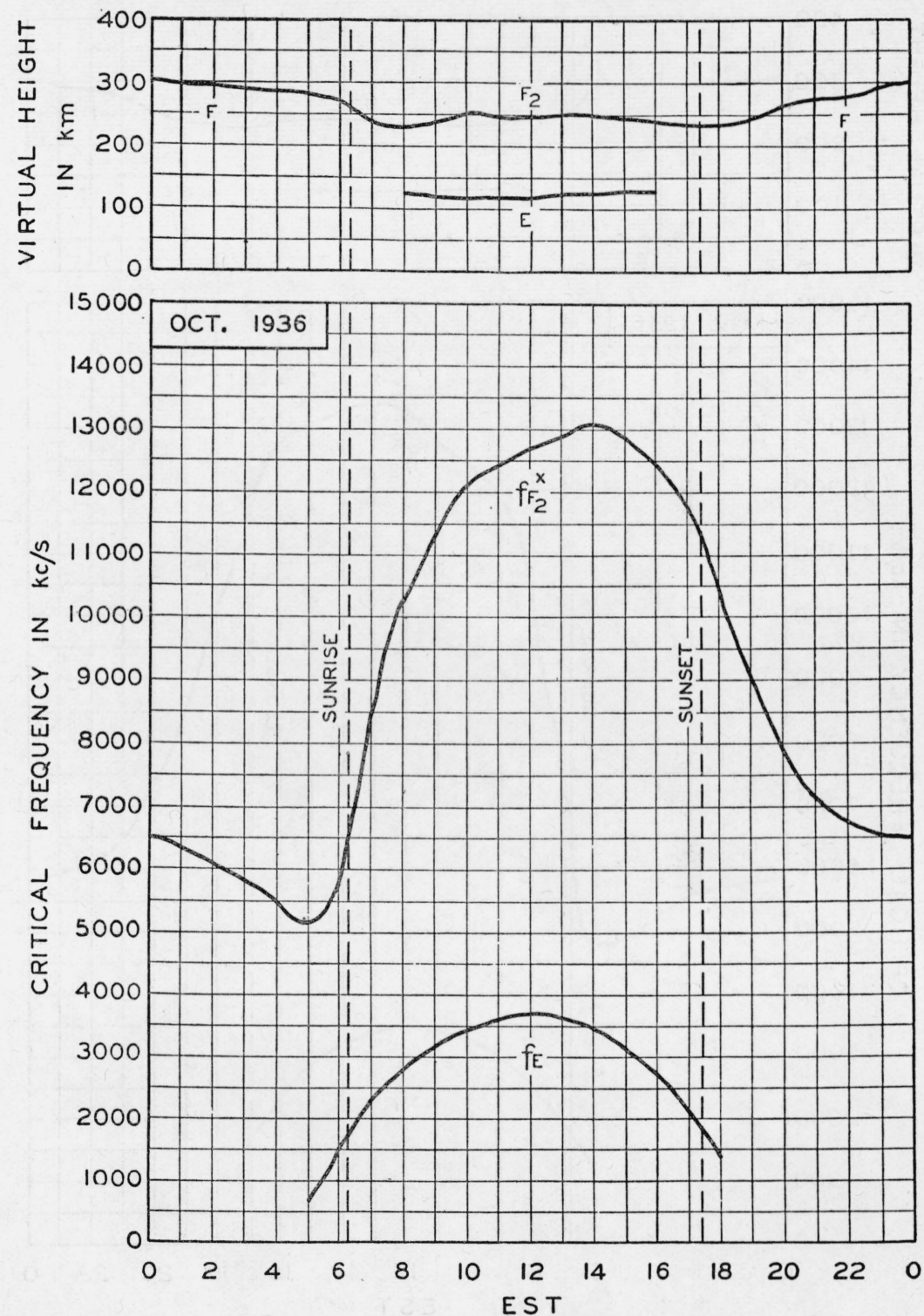

Figure 13.-Critical frequencies and virtual heights for October 1936. Curves represent hourly averages. 

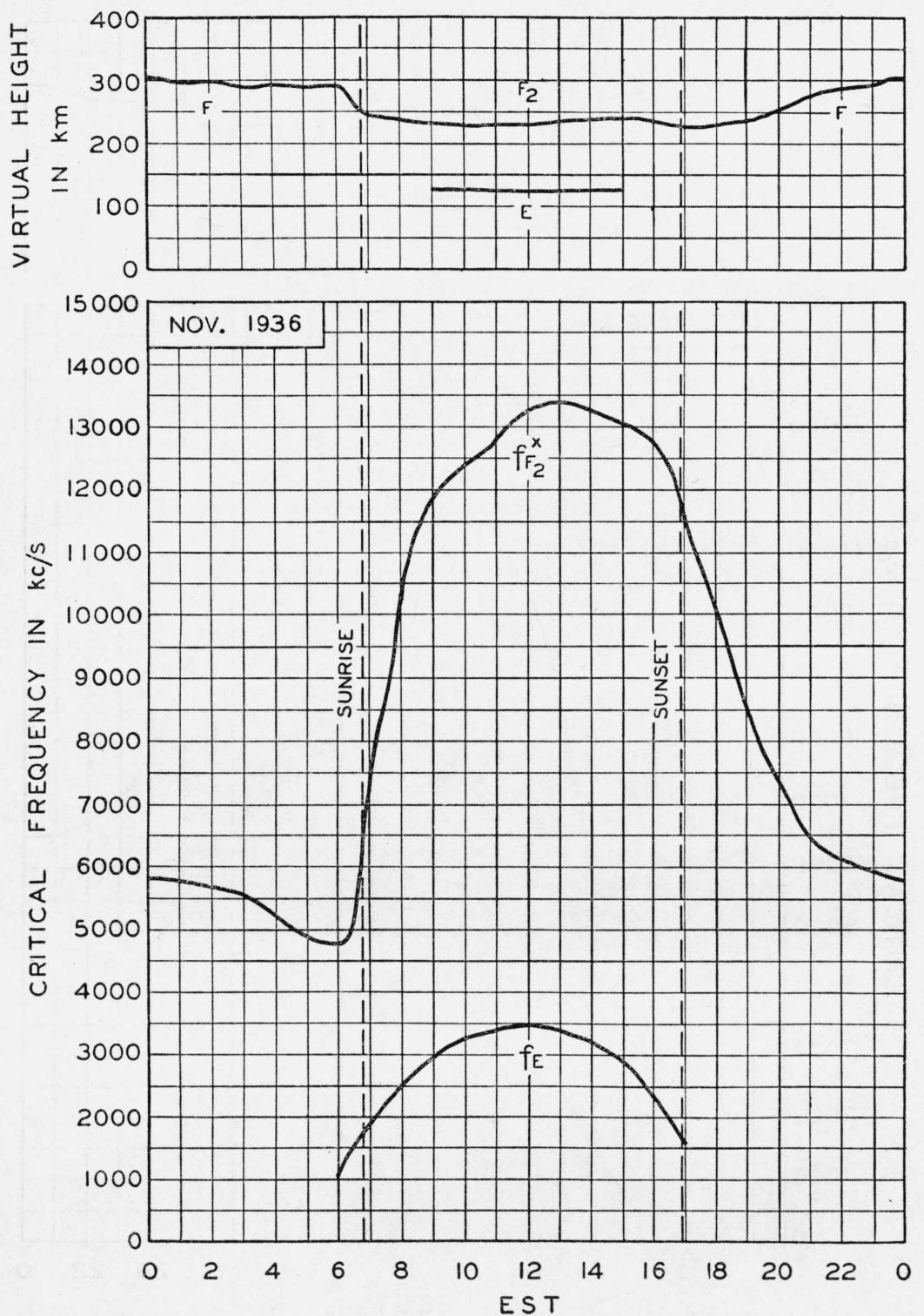

Figure 14.-Critical frequencies and virtual heights for November 1936. Curves represent hourly averages. 

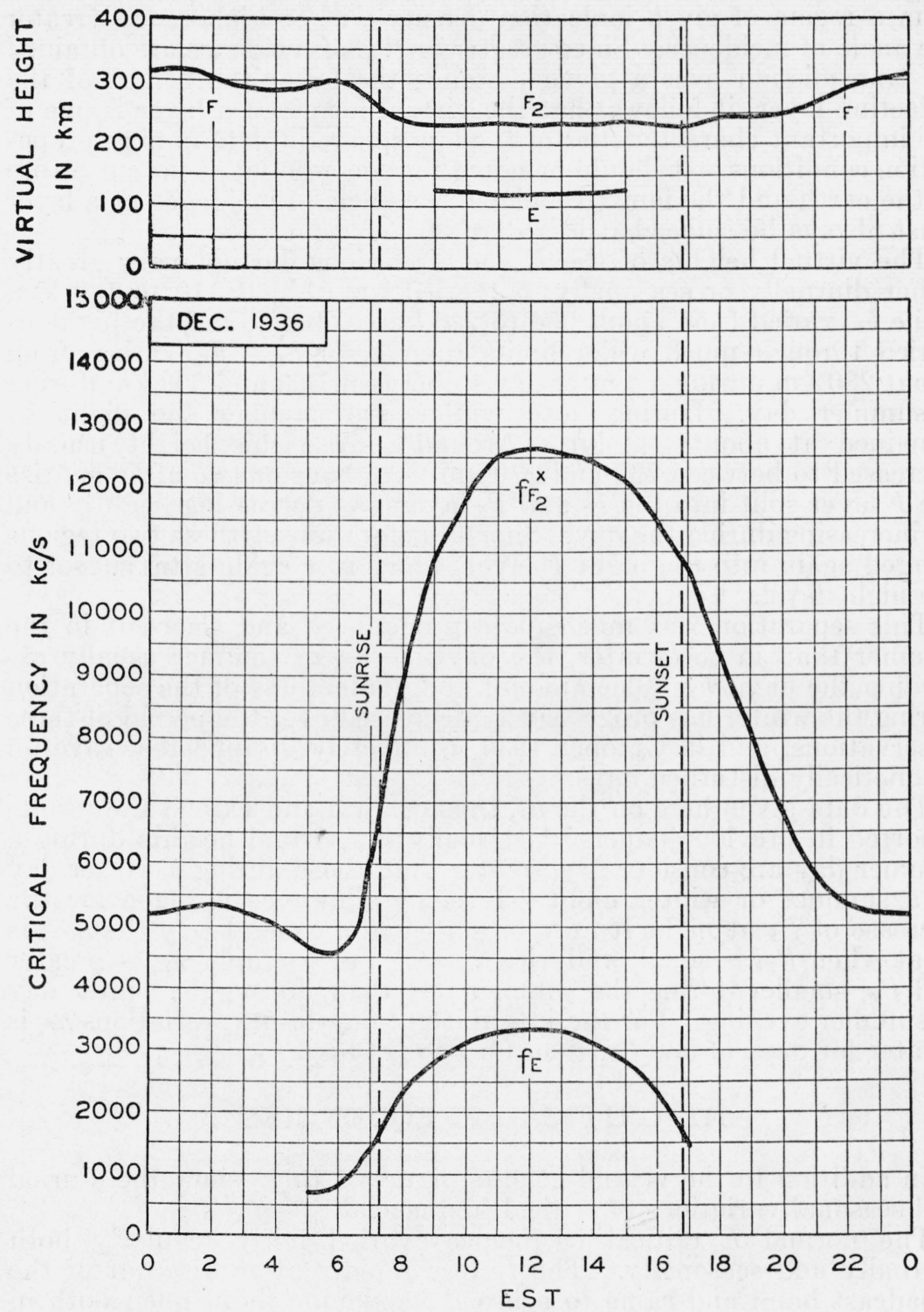

FIGURE 15.-Critical frequencies"and virtual heights for December 1936. Curves represent hourly averages. 


\section{VIRTUAL HEIGHTS}

Referring to these figures, we shall consider first the virtual heights. In general, the maximum frequency of waves which may be returned from a region of given ionization density will be higher, the greater the angle of incidence. Since greater angles of incidence are obtained for transmission over a given distance the lower the height of the reflecting layer, it follows that the virtual height of a layer is one of the important characteristics of the ionosphere in determining propagation conditions. It should be noted that on account of the curvature of the earth and the ionized regions, the angle of incidence at a layer must always be somewhat less than $90^{\circ}$.

The virtual heights of the $E$ and $F_{1}$ regions did not vary greatly either diurnally or seasonally; $h_{E}$ varied from about 110 to $130 \mathrm{~km}$, while $h_{F_{1}}$ varied from about 200 to $240 \mathrm{~km}$. The $h_{F_{2}}$ and the night $h_{F}$ varied through much wider limits than $h_{B}$ or $h_{F_{1}}$. $h_{F_{2}}$ varied from about $230 \mathrm{~km}$ during a winter day to between 350 and $500 \mathrm{~km}$ during a summer day. During both winter and summer the night $h_{F}$ remained at about $300 \mathrm{~km}$. Around sunrise this height usually decreased to between 230 and $270 \mathrm{~km}$. An hour or two after sunrise the $F$ layer split into the $F_{1}$ and $F_{2}$ layers, $h_{F_{1}}$ decreasing slightly and $h_{\mathrm{F}_{2}}$ increasing during the day. Shortly before sunset these two regions merged again into the night $F$ layer, which rose again after sunset to the night level.

This separation was much more pronounced and clear-cut in the summer than in the winter, the daytime $h_{F 2}$ in summer usually exceeding the night $h_{F}$. The amount and distinctness of the separation during the winter has progressively decreased over the period of these observations, and in October 1936, completely disappeared, save on magnetically disturbed days.

The data given here on the $h_{F_{2}}$ thus confirm and extend the results reported in previous papers. ${ }^{3}{ }^{4}$ Usually the virtual heights during a summer day are considerably greater than those during a winter day or a summer or winter night. If some allowance is made for the decrease of $f_{r}^{x}$ at night it may be stated in a general way that $h_{F_{3}}$ is great when $f_{F_{2}}^{x_{2}}$ is small, and vice versa. For example, $h_{F_{2}}$ is greater and $f_{F_{2}}^{x}$ smaller during the summer day than during the winter day or summer evening. For the intermittent day-to-day variations $h_{F_{2}}$ is greater for days of low $f_{F_{2}}$ than for days of high $f^{x} F_{2}$.

\section{CRITICAL FREQUENCIES}

In addition to the virtual heights, figures 1 to 15 show the diurnal and seasonal variations of critical frequencies.

The normal $E$ critical frequencies varied fairly regularly both diurnally and seasonally. The $f_{B}$ rose rapidly at sunrise out of the broadcast band and came to a broad maximum about noon both in summer and in winter. The summer values were greater than the winter values. The diurnal variation of $f_{E}$ was symmetrical about noon. Neglecting the sporadic $E$, the values at sunrise were about the same as those at sunset. Some observations made at night indi-

\footnotetext{
${ }^{3}$ E. O. Hulburt, Theory of the ionosphere. Terr. Mag. 40, 193 (1935).

E. B. Judson, Comparison of data on the ionosphere, sunspots, and terrestrial magnetism. J. Research NBS 17, 323 (1936).
} 
cated that the $f_{B}$ at that time was usually found between 600 and $1,000 \mathrm{kc} / \mathrm{s}$. There was a long time increase of $f_{B}$ as well as of the other regions which will be discussed later.

The $F_{1}$ critical frequencies varied fairly regularly when they were observed, i. e., principally during the summer day. Both the ordinary and extraordinary $F_{1}$ rays were then normally found, the extraordinary ray being much weaker. $F_{1}$ critical frequencies never occurred at night since the $F_{1}$ layer lost its identity as a separate layer and merged with the $F_{2}$ layer shortly before sunset. They were also usually poorly defined or absent during the winter day. There was a long time year-to-year increase of $f_{F_{1}}$ similar to that for $f_{E}$. During the period of this increase the $f_{F_{1}}$ became less and less well defined, especially during the winter, until, in October 1936, it usually could not be found.

The diurnal variations of the $f_{F_{2}}^{x}$ may be classified into two general types: the winter type, centered in December, and the summer type, centered in June. In the winter type the $f^{x} F_{2}$ began rising about onehalf hour before sunrise and rose rapidly until 2 or 3 hours after sunrise, coming to a broad maximum centered about 1300 local time. It fell fairly rapidly from about 2 hours before until 3 hours after sunset and then more slowly during the night. The night decrease was not smooth but was broken up by plateaus and secondary maxima. The maximum at about 4 a. m., first observed in 1933 at the National Bureau of Standards, ${ }^{5}{ }^{6}$ has become progressively less and less marked in successive winters since the sunspot minimum in 1933. The minimum for the 24 hours usually occurred about an hour before sunrise. Except for rare occasions, on days of magnetic storms the day-to-day variations in the $f_{F_{2}}^{x}$ curves were small. Thus the behavior of the ionosphere was nearly always regular during the winter, and, indeed, could be predicted over short periods. This was especially true during the latter part of the period covered in this paper.

In the summer type the morning increase in $f^{x} F_{3}$ began about sunrise. It occurred considerably later with respect to sunrise and was much slower than in the winter type. The $f_{F_{2}}$ continued to rise in this manner until about 4 hours after sunrise, after which it rose less rapidly during the remainder of the day.

The maximum occurred at about sunset, and was followed by a very slow and more regular decrease through the night, until the minimum was reached just before sunrise. The day-to-day variations in the $f_{F_{2}}^{x}$ were in general greater in summer than in the winter time, and the behavior of the ionosphere could not be predicted as well, although the general shape of the diurnal curves was the same from day to day in the summer.

During the spring and fall the transition between winter and summer characteristics did not take place gradually, as would appear from the average curves, but the diurnal variation shifted erratically back and forth between the two types. In general, the whole day was of one type, although the value of $f_{F_{2}}^{x}$ differed widely on different days. The general shift in the average curves represents a relative predominance of winter or summer conditions during the month.

It may be seen from the graphs that the maximum $f_{F_{2}}^{x}$ for the year occurred during the winter day and a lesser maximum occurred near

s. T. Gilliland. Ionospheric investigations. Nature (London) 134, 379 (1934).

6 T. R. Gilliland. Multifrequency ionosphere recording and its significance, J. Research NBS 14, 283 (1935); Proc. Inst. Radio Engrs. 23, 1076 (1935). 
sunset in summer. Both maxima were fairly broad and indicated that a frequency near the maximum transmission frequency might be used for 8 or 9 hours during the day. This time centered at about 1300 local time during the winter and at about sunset during the summer.

\section{LONG-TIME EFFECTS}

Since the sunspot minimum in the winter of 1933-34 the critical frequencies of the $E, F_{1}$, and $F_{2}$ regions have increased over a long: period which is associated with the 11-year sunspot cycle. This longtime increase was superimposed on the seasonal variations and may be seen in figures 1 to 15 . The largest and most striking long-time changes occurred in the $f_{F 2}^{x}$.

\section{INTERPRETATION AND APPLICATIONS}

The three principal properties of the ionosphere affecting sky-wave transmission are absorption, virtual height, and critical frequency.

Absorption.- The absorption of radio waves in the ionosphere determines the maximum distance and minimum frequency for practical high-frequency communication. The absorption varies in general with time of day, season, frequency and length of path. Absorption seems to take place mainly in the lower ionosphere, that is in the $E$ layer or below. The absorption is greater during the summer day than during the winter day. It is greater for the lower high frequencies, that is, those frequencies which are close to or below the $E$ critical frequency for a given distance. It is usually greater during the day than during the night, especially for these lower high frequencies. The evidence indicates that a higher frequency at large angles of incidence behaves, with respect to absorption, like a much lower frequency at small angles of incidence.

The effect of absorption at different frequencies is illustrated by field-intensity measurements of two transmitting stations about 600 $\mathrm{km}$ distant, one at $6,060 \mathrm{kc} / \mathrm{s}$ and the other at $9,570 \mathrm{kc} / \mathrm{s}$. Measurements on the 6,060-kc transmission indicated day field intensities about 2 percent of the night field intensities. For this distance this frequency was below the $E$-critical frequency for several hours during the day. Similar measurements on the 9,570-kc station indicated day field intensities of approximately the same intensity as the night field intensities. For this distance this frequency was well above the $E$-critical frequency at all hours of the day. These two examples illustrate the advantage of using a transmission frequency well above $f_{E}$ if $f^{x} F_{2}$ is high enough to reflect transmissions at such frequencies.

Virtual height.- The virtual height is an important characteristic of an ionized layer for determining the maximum frequency for which the waves will be reflected from the layer. For a given transmission distance the angle of incidence at a layer will be greater the lower the layer. On account of the curvature of both the earth and the ionized layers, the maximum possible angle of incidence is also greater the lower the layer. Since the critical frequency for a given ionization density varies approximately as the secant of the angle of incidence, it follows that for a given ionization density and distance a lower layer can reflect waves of a higher frequency. It is thus apparent that even though the E-layer ionization density is lower than that of the $F_{2}$ 
layer, the former may frequently determine the maximum usable frequency. Because of the high $f_{B}$ and low $f_{P_{2}}$ during the summer day, this condition exists fairly regularly at that time. This condition also exists during days of severe magnetic disturbances when the $f_{F_{2}}^{x}$ is especially low and $h_{F_{2}}$ is abnormally great in these latitudes. Sporadic $E$ reflections frequently control long-distance transmissions both day and night. Good sporadic $E$ reflections often provide intense signals at high frequencies and sometimes at ultrahigh frequencies. These reflections are very common during the summer but occur at irregular intervals. The irregularities are both geographical and temporal.

For frequencies near the critical frequency the virtual heights increase rather rapidly and are considerably greater than the minimum values shown in the graphs, but undergo similar diurnal and seasonal variations. Since this is so the virtual height diminishes as the angle of incidence increases for a given frequency and the angles of incidence for several paths cannot be calculated from a single virtual height. Therefore, a knowledge of the actual variation of the virtual height with frequency is necessary in order to calculate accurately the maximum usable frequency or the skip distance. In the interests of brevity the variations of virtual heights with frequency are not presented here, but typical examples of such variations may be found in many of the papers on the ionosphere.

The following tabulation gives a conservative estimate of the factors by which the normal-incidence critical frequency may be multiplied to obtain approximately the maximum usable frequency over long distances, $2,500 \mathrm{~km}$ or more.

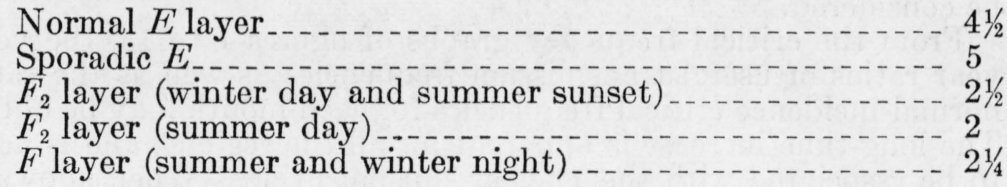

Reception measurements indicate that these values may be modified by the slope of the land, near the transmitter or receiver, in the path of the wave. The reason for this is that the slope of the land affects the distribution of intensity of the energy transmitted or received in a given vertical plane, especially at low angles.

Critical frequency.- In contrast to the effect of absorption, the ionization density, measured by critical frequency, largely determines the minimum distance range and maximum frequency for practical high-frequency radio communication.

Because of the high $f_{F_{2}}^{x}$ and the low $f_{E}$ during the winter day, the highest frequencies are transmitted by way of the $F_{2}$ layer at this time. During the summer day, however, $f^{x}{ }_{n}$ is much lower and $f_{B}$ is higher than in winter so that the band of frequencies which can penetrate the $E$ layer and be returned by the $F_{2}$ layer is very small or nonexistent. This effect is increased for the reason that $h_{F_{2}}$ is greater in summer than in winter. Hence most long and medium distance transmission during the summer is by way of the $E$ layer. The frequent occurrence of sporadic $E$ reflections during the summer, both by day and by night, increases the likelihood of such transmission. In general, it should be noted that the probability of $E$-layer transmission over long distances is greater than over short distances of a few hundred kilometers, other things being equal. 
The $F_{2}$-layer is capable of reflecting higher frequencies during the winter day than at any other time. This condition exists for a period of 7 or 8 hours, centered at about 1300 local time at the place where the wave strikes the layer. The most favorable time for transmission to the west is thus later than for transmission to the east. In the summer, however, the $F_{2}$ layer can reflect higher frequencies for a period of 7 or 8 hours around sunset at the place where the wave strikes the layer than at any other hour of the day. The period of lowest $f_{p}$ and consequent lowest maximum frequencies which can be reflected from the $F$ layer occurs about an hour before sunrise, both summer and winter. Because of the slow decrease of $f_{F}$ during the late summer evening, $F$ transmission of higher frequencies is more likely then than during the late winter evening.

Normal $E$ transmission will take place at the highest frequencies around noon local time. Sporadic $E$ reflections are especially useful for transmission in the summer morning and evening.

The $F_{1}$ layer is normally useless for transmission save for short distances and for a very limited band of frequencies, and does not need to be considered from a transmission standpoint. The reason for this is that $f_{F_{1}}$ is not sufficiently above $f_{B}$ for a wave to penetrate the $E$ layer and be reflected from the higher $F_{1}$ layer, at least at fairly large angles of incidence.

For single-reflection transmission the controlling portion of the ionosphere is halfway between the terminal points. For multireflection transmission, the ionosphere along the entire path, except for that portion within several hundred kilometers from the terminal points, must be considered.

From the critical frequency graphs of figures 1 to 15 , the year-toyear ratios of useful transmission frequencies as well as the ratios of normal-incidence critical frequencies for each month may be obtained. The long-time increase is apparent for all the regions, and is believed to be associated with the 11-year sunspot cycle. When allowance is made for the seasonal variations, $f_{B}$ and $f_{F_{1}}$ are seen to have increased by a factor of about 1.3, during the period of these observations. During the same period the $f_{F_{2}}$ increased by a factor of about 1.9. The effect of the general increase in critical frequencies is to raise the maximum usable frequencies proportionally and also to increase the absorption on the medium-high frequencies. This means that the most effective frequencies for transmission have increased along with the increase in sunspot activity and may be expected to continue to increase until the sunspot maximum is reached. The sunspot minimum was during the winter of 1933-34 and the next maximum is expected about 1939 .

It should be emphasized that these results are averages and represent data taken systematically and over a long period of time at Washington, D. C. Reports ${ }^{7}$ from Watheroo, Australia, and Huancayo, Peru, indicate that ionosphere conditions are different in the southern hemisphere. Much more comprehensive data will have to be obtained from other latitudes, especially from higher latitudes, before a world-wide picture of the ionosphere may be found. For purposes of transmission, however, the ionosphere may be considered

\footnotetext{
${ }^{7}$ L. V. Berkner, H. W. Wells, and S. L. Seaton. Characteristics of the upper region of the ionosphere. Terr.
} Mag. 41, 173. (1936). 
as essentially uniform, at least over a range of latitude somewhat exceeding that of the United States.

It is believed that current information on ionosphere conditions is of sufficient interest to warrant publication of the future data monthly. It is planned to do this in the form given in figures 13 to 15 , inclusive.

\section{TRANSMISSION IRREGULARITIES}

Two types of transmission irregularities, which are not shown on the average curves, have been observed.

The first type has occurred during fairly severe magnetic storms when the $f_{F_{2}}^{x}$ has been observed to be lower, the $h_{F_{2}}$ higher and absorption greater than normal during the night of and the day following the local magnetic disturbance. ${ }^{89}$ During a period of such magnetic disturbances the maximum usable frequency was much less than during a magnetically quiet period. A second type of irregularity is the "fadeout,", 101112 a sudden wiping out of practically all high-frequency sky-wave transmission for periods of a few minutes to about an hour. This is caused by a sudden increase in absorption in the lower regions of the ionosphere - the $E$ layer or below-owing to a sudden increase of ionization. This effect is accompanied by a sudden brief disturbance of the earth's magnetic field. The cause of these phenomena is a burst of radiation from a sudden solar eruption. No relation has been observed between this effect in the lower ionosphere and the magnetic storm effect in the higher ionosphere, as entirely different regions of the ionosphere are concerned.

\section{CONCLUSIONS}

The general form of the diurnal and seasonal variations of the critical frequencies and virtual heights has recurred from year to year. The daytime critical frequencies of the $E$ and $F_{1}$ regions were symmetrical about noon, reaching a diurnal maximum at noon and a seasonal maximum in midsummer. The diurnal maximum of $f_{F_{2}}^{x}$ occurred at about 1300 local time in the winter and at about sunset in the summer. The diurnal maximum in winter was much greater than in summer. The diurnal minimum in both winter and summer occurred about one hour before sunrise. The critical frequency decreased much more rapidly during the winter evening than during the summer evening.

In addition to the seasonal variations there has been a continuous long-time increase of critical frequencies associated with the 11-year sunspot cycle. It was pointed out that this effect increased the upper limit of useful transmission frequencies determined by penetration of the ionosphere and also increased the lower limit of useful transmission frequencies determined by absorption in the lower ionosphere.

Finally, for practical applications, it should be emphasized that the absorption, virtual heights, and critical frequencies of all portions of the ionosphere traversed by the waves must be considered in determining transmission conditions over a given path.

\section{Washington, February 23, 1937.}

${ }_{8}$ S. S. Kirby, T. R. Gilliland, E. B. Judson, and N. Smith. The ionosphere, sunspots, and magnetic storms. Phys. Rev. 48, 849 (1935)

iS. S. Kirby, T. R. Gilliland, N. Smith, and S. E. Reymer. The ionosphere, solar eclipse, and magnetic storm. Phys. Rev. 50, 258 (1936).

$10 \mathrm{~J}$. H. Dellinger. Confirmation of cosmic phenomenon, Science 82, 548 (1935).

$11 \mathrm{~J}$. H. Dellinger. High-frecuency fadeouts continue. QST 20,37(1936).

$12 \mathrm{~J}$. H. Dellinger. Direct effects of particular solar eruptions on terrestrial phenomena. Phys. Rev. 50, 1189 (1936). 